\title{
The management of chronic constipation in pediatric patients
}

\author{
Simona-Gabriela Tudorache ${ }^{1,2}$, Daniela Dobritoiu', Silvia Ragalie', \\ Alin Stoica', Laura-Mihaela Ion ${ }^{1,2}$ \\ ${ }^{1}$ Ponderas Academic Hospital, Bucharest, Romania \\ 2"Titu Maiorescu" University of Medicine, Bucharest, Romania
}

\begin{abstract}
Introduction. Chronic constipation is a common reason for a pediatric patient to visit a doctor and we think that the number of cases is increasing but only a few patients are diagnosed with Hirschsprung disease.

Aim. This study aims to clarify the difference between the two most common causes of chronic constipation in pediatric patients: habitual constipation and Hirschsprung's disease regarding symptoms, clinical findings, investigations and treatment and to identify what is more important for the patients with chronic constipation: to go further with investigations after the clinical examination or to start the medical treatment as soon as possible in orther to establish a conduit in the management of these patients.

Material and method. We present an observational, descriptive and retrospective 4 years study on children diagnosed with chronic constipation.

Results. 122 patients were included in this study, in 3 cases Hirschsprung's disease was diagnosed. As a complication of chronic constipation $58 \%$ of the patients had rectorrhagia and at local examination were found 34 patients with fecaloma, 32 with anal fissure and 5 with hemorrhoids, but none of these findings were associated with Hirschsprung disease. Only in $36 \%$ of the cases further investigations were needed. The average age at the first examination was 4 years and 3 months and the average age for the patients with rectorrhagia was 5 years and 3 months.

Conclusions. The number of children with chronic constipation is increasing. Rectorhhagia, fecalomas, anal fissures and hemorrhoids are associated with habitual constipation but not with Hirschsprung disease. Because of the small number of cases diagnosed with Hirschsprung disease, the fact that the mean age of the children with rectal bleeding is 1 year higher than the one of the group and the small percentage of further investigation needed, we consider that in order to early prevent complications personalized medical treatment is needed and further investigations should not delay the begining of nursing.
\end{abstract}

Keywords: chronic constipation, habitual constipation, Hirschsprung's disease

\section{INTRODUCTION}

Due to the increased number of patients with obesity, feeding difficulties, selective feeding, and allergies or food intolerances, digestive disorders we observed a higher number of patients with difficulty in passing stools. Not all patients with chronic constipation get to be reffered to a pediatric surgeon, therefore the majority of the time only the cases that present complications of an untreated constipation or cases reluctant to diet or to medicated treatment are.

The constipation defining criteria are: 2 or less defecations per week, at least 1 fecal incontinence episode per week, history of voluntary retention of feces, history of recurrent abdominal pain, history of voluminous fecal mass (fecaloma), history of voluminous stools $[1,2,3]$.

The pediatrician's consult is very important because is essential to exclude or to early diagnose the possible medical causes that take to occurance of constipation. The pediatrician must know when is the right time to refer a child with chronic constipation to a pediatric surgeon. The food intolerance cases or other causes relating to digestion are treated by the pediatrician or by the pediatric gastroenterologist [4].

The differential diagnosis for chronic constipations included organic and functional causes. Thus, the most frequent causes for chronic constipation in 
children are: functional constipation, Hirschsprung disease and its associated diseases, internal sphincter achalasia, anterior perineal anus, chronic or acute anal fissures, Crohn's disease, different systemic diseases: hypothyroidism, uremia, hypercalcemia, neurological diseases; psychiatric disorders and their medications; anticonvulsant drugs and anticholinergics [1].

The most frequent cases that get to a surgeon are the ones where differential diagnosis between functional or habitual constipation and congenital megacolon is needed. Functional constipation is voluntary or involuntary retention of feces that results in congestion of intrarectal feces (forming fecalomas), passing stool thus becoming painful. Congenital megacolon (Hirschsprung's disease) is a disease in which ganglionar cells from the Meissner and Auerbach nervous plexus are absent, most often affecting the distal part of the colon, the rectosigmoid area. Absence of these cells results in the impossibility of passing stool through this area (which appears narrowed at barium enema) and, thus, in accumulation of feces above the affected area, the overlying area getting distended [5].

\section{OBJECTIVES}

The purpose of this study is to clarify the difference between habitual constipation and Hirschsprung's disease regarding symptoms, clinical findings, investigations and treatment and also to identify what is the most important thing which helps these patients in order to prevent complications: to go further with investigations after clinical examination or to start the treatment as soon as possible. And in the end we want to establish a conduit in the management of these patients.

\section{MATERIAL AND METHOD}

\section{Study design}

This is a descriptive, observational and retrospective study, performed during a four years period (January 2017-October 2020) and includes all pediatric patients diagnosed with constipation at Ponderas Academic Hospital in the Pediatric Surgery Department.

Inclusion criteria are: age $<18$ years old, time of the consult (presentations between January 2017 untill October 2020), patiens diagnosed with chronic constipation, anal fissure, rectal bleeding and Hirschsprung's disease.

Exclusion criteria included: age $>18$ years, other period of the consult, other diagnosis than the ones mentioned among the inclusion criteria, patients at the first episode of constipation, in most cases due to environmental changes or after enterocolitis episode or after antibiotic treatment, patients with rectal bleeding without constipation, stool with mucus and blood in children with disenteriform enterocolitis or food and medicine allergies and intolerances.

\section{Statistical analysis}

To collect the data, the hospital's computer system was used - MedPractice, MCM and Xero. In Ponderas Academic Hospital, all data related to patient's history are stored in electronic format, the consults, imagistic and laboratory investigations conducted in the hospital or in the Regina Maria network, as well as those brought by the patients from other hospital centers, are added the patient's charts, thus achieving an overall, personalized, complete and complex view over every case. There was created a database and analysed using IBM SPSS v.20 in orther to establish if there is a statistical significance of correlations between the variables (time of the first consult, gender, age, clinical findings, further investigations, diagnosis, treatment). In order to realize the tables and graphics, we imported the results in Excel. The statistics were determined according to the biostatistics recommendations in current medical practice [6].

\section{Medical ethical issues}

Being a retrospective study, we used the national medical consent obtained from the parents at the time of the consult, no further consent was necessary and for the analysis of the medical charts and history we obtained the hospital's ethics comitee permission no. 172/19.05.2021.

\section{RESULTS}

163 patients with constipation were initially included in the study, but 41 patients were excluded because they did not complete the inclusion criteria.

Thus, a representative group of 122 patients was selected, out of which 61 are females and 61 are males. We diagnosed 3 patients with Hirschsprung disease and they were male.

20 patients were examined in 2017, 21 patients in 2018, 41 in 2019 and 40 in 2020 (figure 1).

They all had constipation as a reason to come for a consult, some also having associated abdominal pain, abdominal distension, pain at defecation, nausea and rectal bleeding as seen in figure 2. 2 of the three patients diagnosed with Hirschsprung disease associated abdominal pain. 


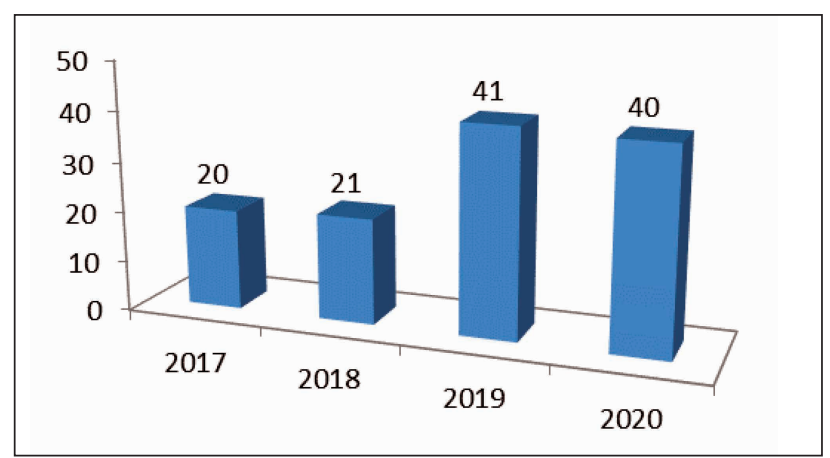

FIGURE 1. Year distribution of the patients

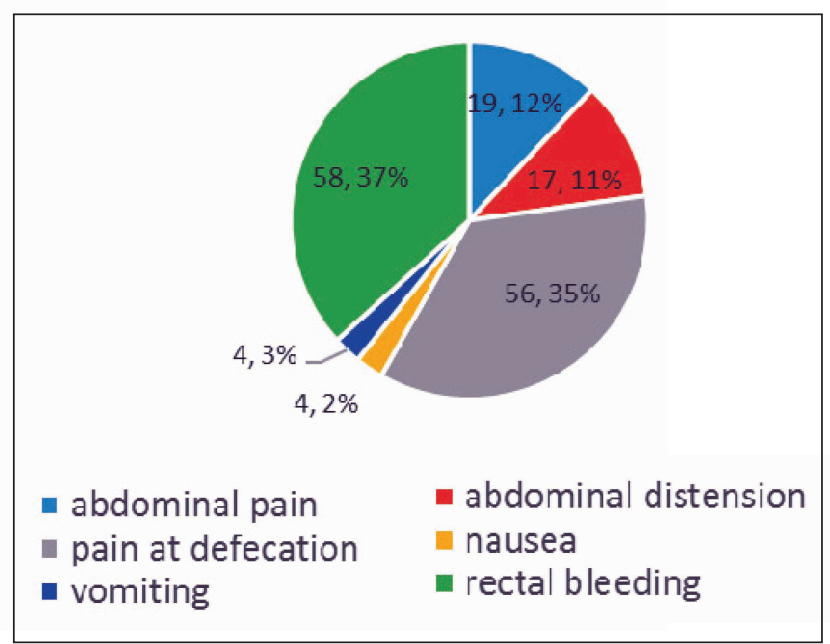

FIGURE 2. Other reasons for visiting the doctor in the patients with chronic constipation

The patients with abdominal pain did not need emergency surgery, as they diagnosed with acute abdomen.

We divided the patients in 4 age groups (table 1) and the highest incidence of chronic constipation is observed between 3 and 7 years of age, but no patient with Hirschsprung's disease was diagnosed at this age.

At the local clinical examination, the most cases where the fecaloma was found are between 1 and 7 years of age $-73 \%$, and the highest number of complications (rectorrhagia, anal fissure, hemorrhoids) of chronic constipation was observed in children older than 3 years of age $-72 \%$.

In order to determine if there is a statistical difference between the mean age of the patients with chronic constipation and the mean age of the patients with rectorrhagia, we proposes the null hypothesis which states that there is no difference and thested it using the t-Student test. Because the variable tStat $(15,77)$ it's higher than tCritical $(1,979)$ we reject the null hypothesis and we admit that there is a statistically significant difference between the means of the two groups. This is also related to the patients' average age at the first examination which was 4 years and 3 months and the average age for the patients with rectorrhagia which is 5 years and 3 months.

TABLE 2. $t$-Test: Paired two sample for means (general mean age and mean age of patients with rectorhhagia)

\begin{tabular}{|l|r|r|}
\hline & General mean age & $\begin{array}{r}\text { Mean age of } \\
\text { patients with } \\
\text { rectorrhagia }\end{array}$ \\
\hline Mean & 51.54918033 & 0.475409836 \\
\hline Variance & 1290.712437 & 0.251456442 \\
\hline Observations & 122 & \\
\hline Pearson correlation & 0.317975886 & \\
\hline $\begin{array}{l}\text { Hypothesized mean } \\
\text { difference }\end{array}$ & 0 & \\
\hline$d f$ & 121 & \\
\hline $\mathrm{t}$ Stat & 15.77090146 & \\
\hline $\mathrm{P}(\mathrm{T}<=\mathrm{t})$ one-tail & $1.97291 \mathrm{E}-31$ & \\
\hline $\mathrm{t}$ Critical one-tail & 1.657544319 & \\
\hline $\mathrm{P}(\mathrm{T}<=\mathrm{t})$ two-tail & $3.94581 \mathrm{E}-31$ & \\
\hline $\mathrm{t}$ Critical two-tail & 1.979763763 & \\
\hline
\end{tabular}

To see if there is a statistically corelation between the patients diagnosed with Hirschsprung's disease and the one diagnosed with habitual constipation regarding clinical findings (fecaloma, rectorrhagia, anal fissure or hemorrhoids), we run the Pearson's corelation test (table 3 ) and discovered that there was no association between the disease and this clinical findings (Pearson coefficient $>0.7$ ). The only correlation with mild statistical significance is between rectorrhagia and anal fissure (Pearson coefficient $=0.477$ ).

From the total number of patients, only in $36 \%$ of the cases we need to perform further investigations after the clinical examination - in 45 cases we performed an abdominal ultrasound, in 7 irigography and 5 had rectal biopsies taken. Most abdominal ul-

TABLE 1. Age groups distribution and clinical findings

\begin{tabular}{|c|c|c|c|c|c|c|}
\hline $\begin{array}{c}\text { Age Groups } \\
\text { (months) }\end{array}$ & $\begin{array}{c}\text { Number of } \\
\text { patients }\end{array}$ & $\begin{array}{c}\text { Hirschsprung's } \\
\text { disease }\end{array}$ & Fecaloma & Rectorrhagia & $\begin{array}{c}\text { Anal } \\
\text { fissure }\end{array}$ & Hemorrhoids \\
\hline $0-12$ & 14 & 1 & 4 & 2 & 3 & 0 \\
\hline $13-36$ & 41 & 2 & 13 & 16 & 5 & 0 \\
\hline $37-84$ & 47 & 0 & 12 & 25 & 15 & 2 \\
\hline $85-216$ & 20 & 0 & 5 & 16 & 9 & 3 \\
\hline
\end{tabular}


TABLE 3. Pearson test

\begin{tabular}{|c|c|c|c|c|c|}
\hline & $\begin{array}{c}\text { Hirschsprung's } \\
\text { disease }\end{array}$ & fecaloma & rectorrhagia & $\begin{array}{c}\text { anal } \\
\text { fissure }\end{array}$ & hemorrhoids \\
\hline Hirschsprung's disease & 1.000 & -0.095 & -0.151 & -0.095 & -0.033 \\
\hline Fecaloma & -0.095 & 1.000 & -0.120 & -0.144 & -0.029 \\
\hline Rectorrhagia & -0.151 & -0.120 & 1.000 & $\mathbf{0 . 4 7 7}$ & 0.217 \\
\hline Anal fissure & -0.096 & -0.144 & $\mathbf{0 . 4 7 7}$ & 1.000 & -0.029 \\
\hline Hemorrhoids & -0.033 & -0.029 & 0.217 & -0.029 & 1.000 \\
\hline
\end{tabular}

trasounds had normal findings, but 5 patients were found with associated gallbladder malformations, as its flexure.

Most patients were diagnosed with habitual constipation and they were reactive to the igieno-dietary measures and to laxatives, ending the investigation protocol due to the therapeutic success. 3 patients being diagnosed and treated for congenital megacolon, 2 of them having rectal biopsies which not confirmed the diagnosis suspicion.

The patients diagnosed with Hirschsprung's disease were treated in our hospital, by elective surgery. All patients with congenital megacolon received preoperative rectal biopsies, thus obtaining diagnostic certainty. The form of the Hirschsprung's disease was short, rectosigmoidian in all three patients and none of them needed colostomy post-operative or later after. An intraoperative extemporaneous histopathological exam was also used to check the colonic segment lowered for anastomosis for presence of fibers and ganglionar cells. For the three patients the surgical technique included laparoscopic Duhamel trans abdomino-perineal recto-rectal pull-through with colo-anal anastomosis using mechanical suture with a linear stapler for the septum between the posterior rectal wall and lowered anterior ganglionar colon. None of the patients presented with pre- or post-operative enterocolitis and none developed incontinence or stenosis. The hospitalization time was 4 days and none of the patients needed to be readmitted.

\section{DISCUSSION}

The study of Rajindrajith et al. emphasises that in recent period the number of cases of chronic constipation in pediatric patients is raising, constipation is affecting $0.7-29.7 \%$ of children across the world [7] and more than that is an underestimated but common health problem worldwide, decreasing the quality of life, facts approved also by the Levy et al. study [8]. In our study, the number of patients in the last two years is double than the one diagnosed in the previous period.

The most cases of children with chronic constipation included in this study were in age group 1-3 years and 3-7 years, as Xinias et al. say in their study that the peak incidence of constipation occurs between 2 and 4 years of age, when the toilet training starts [9].

The literature confirms that there is a higher rate of Hirschsprung's disease in male gender, with a M:F ratio of $4: 1[1,10,11]$.

In our study, the gender repartition between males and females in examined children with chronic constipation is equal, associating it more with feeding habits and with the environment, most studies report similar prevalence rates for boys and girls [12]. However, the patients that underwent surgery for congenital megacolon were males.

De La Torre et al. observed that Hirschsprung's disease can manifest clinically as a bowel obstruction in neonates, chronic constipation in older children or directly as enterocolitis [12]. All the 3 patients diagnosed with Hirschsprung's disease included in this study have had chronic constipation, no bowel obstruction or enterocolitis were observed.

In their study which included 962 children, Loening-Baucke et al. concluded that constipation was the most common cause of acute abdominal pain in children [13]. As reasons for visiting the doctor accompaning the chronic constipation $56 \%$ of the patients included in our study have associated abdominal pain, from literature as Leung et al. said in his study, children with functional constipation may present with intermittent abdominal pain usually localized to the periumbilical area [14]. De Lorijn et al. observed that abdominal pain is common in Hirschsprung's disease [15]. And so we can conclude that abdominal pain is an accompanying symptom for both Hirschsprung's disease and habitual constipation.

The "red flags" suggestive of organic causes of constipation include rectal bleeding/blood in the stool unless attributable to an anal fissure can be signs of Hirschsprung's disease-associated toxic enterocolitis, as Leung says in his study [14]. 58\% of the patients included in our study associated rectal bleeding as the most common complication and with statistically significance we observed an association of them with anal fissures. None of our patients associated Hirschsprung's disease enterocolitis.

After a general examination of the patient, as Baker et al. observed in their study, that also reflect the 
medical position statement of the North American Society for Pediatric Gastroenterology and Nutrition, rectal examination is recommended at least once in the evaluation [16]. Pashankar mentioned in his study that a careful examination is important in the child who presents with constipation. The perianal area should first be examined for evidence of fecal soiling, anterior displacement of the anus, anal fissures, and perianal sensation. In children with Hirschsprung's disease, examination often reveals an empty rectum and the examination may be followed by explosion of flatus and stools [17]. Thus we evaluated the patients for fecalomas, rectorhhagies, anal fissure and hemorrhoids and we can say with statistical significance that none of these clinical local findings were observed in patients diagnosed with Hirschsprung's disease.

The average age of the patients in this group is 4 years and 3 months old, meanwhile the average age of the patients with rectorrhagies is 1 year older. In literature we didn't find an association between the mean age of the children with chronic constipation and the one of the children who associate rectal bleeding to chronic constipation as a complication and so we consider that as a new observation brought by our study.

In Pashankar study is mentioned that thorough history and physical examination are generally sufficient to diagnose constipation in children. The majority of children have functional constipation and do not require any specific diagnostic tests [17]. The majority of children in our study were also diagnosed with functional constipation (only three patient were diagnosed with Hirschsprung's disease) and since only $36 \%$ of the patients needed further abdominal ultrasound or other investigations and the mean age of the patients with rectal bleeding is 1 year higher than the one without complication we think that is more important to start a medical treatment as soon as possible. ERNICA guidelines for the rectosigmoid Hirschsprung's disease mention as recommendations for care that patients should receive saline rectal irrigations 1-3 times per day to decompress the bowel until the definitive pull-through operation [18] and so we can say that nursing is important for both habitual constipation and Hirschsprung's disease.

We used abdominal ultrasound to exclude other pathologies (most patients are heaving also abdominal pain, nausea, vomiting as accompany symptoms to chronic constipation), not to differentiate between functional constipation and congenital megacolon. Some authors investigated the efficacy of pelvic ultrasonography in determining megarectum and fecal load pelvic [19].
Tus, the protocol of investigations for habitual constipation stops here. If Hirschsprung's disease is suspected, a barium enema should be performed "unprepped" as Sood MR mentioned [20] and so we performed 7 irigography - this objectively shows us the existence and length of the narrowed segment in congenital megacolon. The recto-sigmoidian index can be used. It has subunitary values in the short forms of Hirschsprung's disease as Peyvasteh et al. highlighted [21].

If until this point we only had diagnosis suspicions and orientations, certainty is given by rectal biopsy (of the whole colonic wall) - we performed 5 rectal biopsies - this, done transanal or laparoscopically, through anatomopathological examination, tell us if the rectal wall contains the nervous cells and fibers necessary for stool progression and passing as mentioned in Rahman's article which included 216 specimens [22]. A well-executed rectal biopsy with expert pathologic evaluation of the specimen remains the gold standard for the diagnosis of Hirschsprung's disease as is mentioned in Muise et al. study [23].

If the treatment for functional constipation is administered by the pediatrician, the curative treatment for Hirschsprung's disease is surgical and can be done in different operative techniques, the disposition being toward the minimal invasive ones. All three patient diagnosed with Hirschsprung's disease have had a short form, as literature confirms, the short form, rectosigmoidian, is the most frecvent type and represent about $75 \%$ of all [24].

The three patients diagnosed with Hirschsprung's disease were operated laparoscopically. As Georgeson et al. described in his study [25], technology advanced for this pathology as well, with miniature instruments and laparoscopy allowing the use of alternative approaches, minimal invasive over classical. The advantages of the minimal invasive approach are faster postoperative recovery and improved aesthetic aspect. Other advantages are cutting down the intraoperator time, lowering the need for transfusion and avoiding bacterial contamination of the abdominal cavity. The laparoscopic approach is preferred thanks to the vascular intake through the collateral vessels, to the high mobility it has during dissection, to the possibility of transanal removal of resected pieces and to the possibility of using mechanical suturing instruments (stapler), doing transanal [25]. We preffered the Duhamel procedure, some studies indicates that Duhamel procedure performed open versus laparoscopic have the same results on operative time and hospital stay as mentioned in the study of Nah et al. [26].

Based on all the observations from our clinical experience and the results obtained in this study, we 


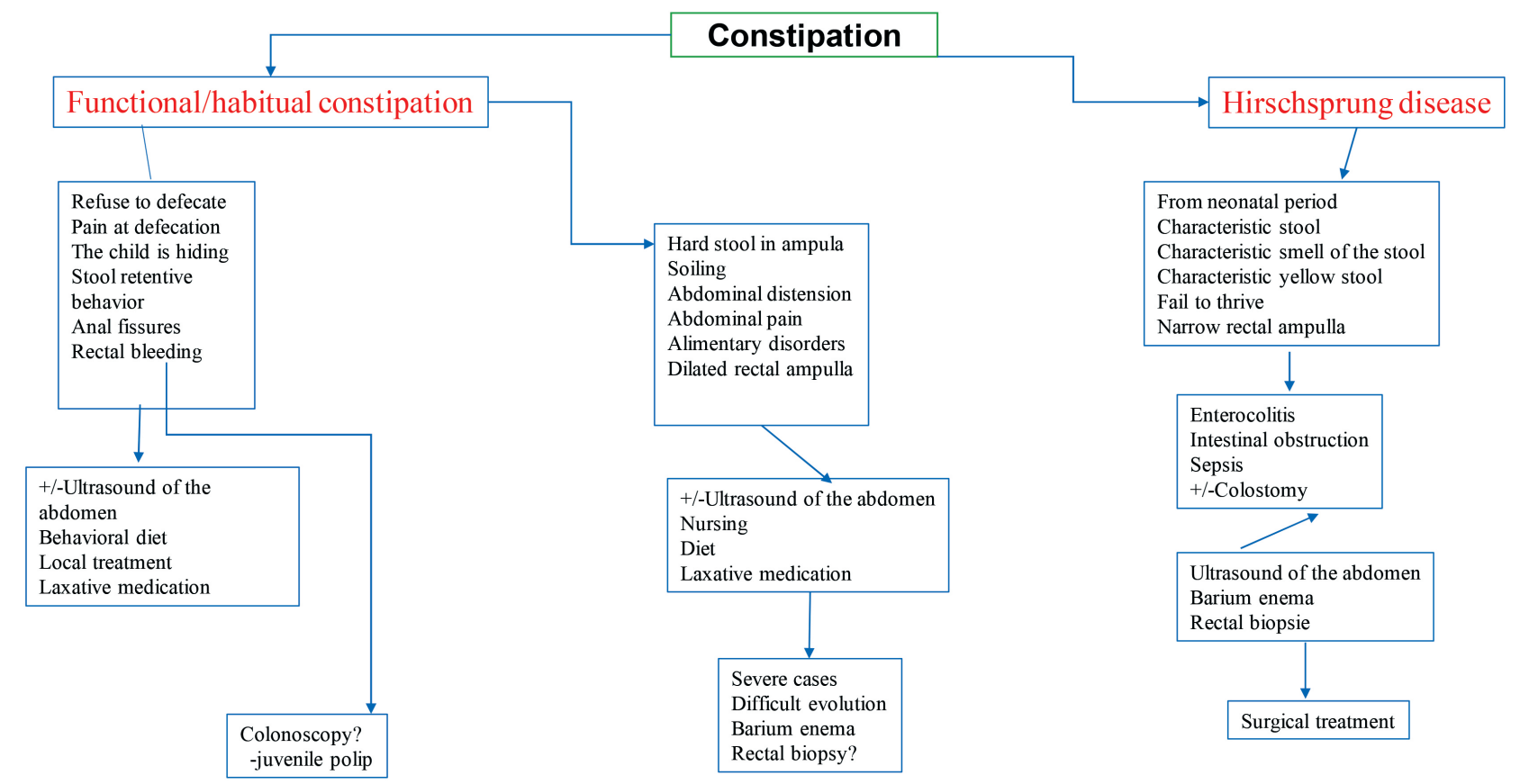

FIGURE 3. The management in children with chronic constipation (authors' own archive)

summarized the management of any child with chronic constipation in figure 3.

Although our results are according to the literature, we consider the small number of patients diagnosed with Hirschsprung disease and treated in our hospital to be a limit of this study. The explanation is that our hospital does not include a Neonatal Department and around $90 \%$ of patients with Hirschsprung disease present during the neonatal period [27], the classic triad of symptoms being delayed passage of meconium ( $>24 \mathrm{~h}$ in term infant), abdominal distension and bilious vomiting [18].

\section{CONCLUSIONS}

The number of children with chronic constipation is increasing. Rectorrhagia, fecalomas, anal fissures and hemorrhoids are associated with habitual constipation not with Hirschsprung disease. Because of the small number of cases diagnosed with Hirschsprung disease, the fact that the mean age of the children with rectal bleeding is 1 year higher than the one of the group and the small percentage of further investigation needed, we consider that in order to early prevent complications personalized medical treatment is needed and further investigations should not delay the begining of nursing. According to the results from our study, in front of a patient with chronic constipation the most important thing is to start as soon as possible the medical treatment and nursing and after we propose the management mentioned before which can be applied in all pediatric centers.

Conflict of interest: none declared Financial support: none declared

\section{REFERENCES}

1. Tietelbaum D, Coran A. Hirschsprung's Disease and Related Neuromuscular Disorders of the Intestine. In: Grosfeld J, O'Neill J, Fonkalsmd E, Coran A (eds.). Pediatric Surgery, 6th edition. Elsevier; 2006:1514-1550.

2. Felt B, Wise CG, Olson A, Kochhar P, Marcus S, Coran A. Guideline for the Management of Pediatric Idiopathic Constipation and Soiling. Arch Pediatr Adolesc Med. 1999;153(4):380-385.

3. Rowan-Legg A; Canadian Paediatric Society, Community Paediatrics Committee. Managing functional constipation in children. Paediatr Child Health. 2011 Dec;16(10):661-70.

4. Khan AR, Vujanic GM, Huddart S. The constipated child: how likely is Hirschsprung's disease? Pediatr Surg Int. 2003 Aug;19(6):439-42.

5. Tudorache SG, Negoiţescu F, Niculescu L. Tratamentul minim invaziv al megacolonului congenital. Ro Med J. 2015;62(3):289-293.

6. Seritan G, Adochitei FC, Enache BA, Petroiu-Andruseac GG, Enache CD, Dascultu A, et al. Guidelines for small size samples biostatistics in current medical practice. International Conference on e-Health and Bioengineering 7th E-Health and Bioengineering Conference (EHB), 7th edition, 2019.

7. Rajindrajith S, Devanarayana NM. Constipation in children: novel insight into epidemiology, pathophysiology and management. J Neurogastroenterol Motil. 2011 Jan;17(1):35-47.

8. Levy El, Lemmens R, Vandenplas Y, Devreker T. Functional constipation in children: challenges and solutions. Pediatric Health Med Ther. 2017;8:19-27.

9. Xinias I, Mavroudi A. Constipation in Childhood. An update on evaluation and management. Hippokratia. 2015 Jan-Mar;19(1):11-9. 
10. Langer J. Hirschsprung's Disease. In: Helcomb G, Patrick M, Dawel $O$ (eds.). Ashcraft's Pediatric Surgery, 6th edition. Elsevier; 2014:474-492.

11. Reynolds M. Hirschsprung Disease - Swenson Pull Through Procedure. In: Chung DH, Chen MK (eds.). Atlas of Pediatric Surgical Techniques. Saunders Elsevier, 2010.

12. De La Torre L, Langer JC. Transanal endorectal pull-through for Hirschsprung disease: technique, controversies, pearls, pitfalls, and an organized approach to the management of postoperative obstructive symptoms. Semin Pediatr Surg. 2010 May;19(2):96-106.

13. Loening-Baucke V, Swidsinski A. Constipation as cause of acute abdominal pain in children. J Pediatr. 2007 Dec;151(6):666-9.

14. Leung AK, Hon KL. Paediatrics: how to manage functional constipation. Drugs Context. 2021 Mar 26;10:2020-11-2.

15. de Lorijn F, Boeckxstaens GE, Benninga MA. Symptomatology, pathophysiology, diagnostic work-up, and treatment of Hirschsprung disease in infancy and childhood. Curr Gastroenterol Rep. 2007 Jun;9(3):245-53.

16. Baker SS, Liptak GS, Colletti RB, Croffie JM, Di Lorenzo C, Ector W, Nurko S. Constipation in infants and children: evaluation and treatment. A medical position statement of the North American Society for Pediatric Gastroenterology and Nutrition. J Pediatr Gastroenterol Nutr. 1999 Nov;29(5):612-26.

17. Pashankar DS. Childhood constipation: evaluation and management. Clin Colon Rectal Surg. 2005 May;18(2):120-7.

18. Kyrklund K, Sloots CEJ, de Blaauw I, Bjørnland K, Rolle U, Cavalieri $D$, Francalanci P, Fusaro F, et al. ERNICA guidelines for the management of rectosigmoid Hirschsprung's disease. Orphanet $J$ Rare Dis. 2020 Jun 25;15(1):164.

19. Karaman A, Ramadan SU, Karaman I, Gökharman D, Erdoğan D, Kacar M, Cavuşoğlu YH, Koşar U. Diagnosis and follow-up in constipated children: should we use ultrasound? J Pediatr Surg. 2010 Sep;45(9):1849-55.

20. Sood MR. Constipation in infants, children, and adolescents: Evaluation. Available at: https://www.uptodate.com/contents/ constipation-in-infants-and-children-evaluation.

21. Peyvasteh M, Askarpour S, Ostadian N, Moghimi MR, Javaherizadeh $\mathrm{H}$. Diagnostic accuracy of barium enema findings in Hirschsprung's disease. Arq Bras Cir Dig. 2016 Jul-Sep;29(3):155-158.

22. Rahman Z, Hannan J, Islam S. Hirschsprung's disease: Role of rectal suction biopsy - data on 216 specimens. J Indian Assoc Pediatr Surg. 2010 Apr;15(2):56-8.

23. Muise ED, Cowles RA. Rectal biopsy for Hirschsprung's disease: a review of techniques, pathology, and complications. World J Pediatr. 2016 May;12(2):135-41.

24. Zhu T, Sun X, Wei M, Yi B, Zhao X, Wang W, Feng J. Optimal time for single-stage pull-through colectomy in infants with short-segment Hirschsprung disease. Int J Colorectal Dis. 2019 Feb;34(2):255-259.

25. Georgeson KE, Robertson DJ. Laparoscopic-assisted approaches for the definitive surgery for Hirschsprung's disease. Semin Pediatr Surg. 2004 Nov;13(4):256-62.

26. Nah SA, de Coppi P, Kiely EM, Curry JI, Drake DP, Cross K, Spitz L, Eaton S, Pierro A. Duhamel pull-through for Hirschsprung disease: a comparison of open and laparoscopic techniques. J Pediatr Surg. 2012 Feb;47(2):308-12.

27. Bradnock TJ, Knight M, Kenny S, Nair M, Walker GM; British Association of Paediatric Surgeons Congenital Anomalies Surveillance System. Hirschsprung's disease in the UK and Ireland: incidence and anomalies. Arch Dis Child. 2017 Aug;102(8):722-727. 